\title{
A New Method of Measuring Human Resource Output Value: An Analysis Based on New Understanding of Value Chain
}

\author{
Yuewu Wang, Sichao Wang, Lily Wang \\ School of Business Administration, Hunan University, Changsha, China \\ Email: wyw6264@sina.com, 1727742945@qq.com,wll228866@126.com
}

How to cite this paper: Wang, Y. W., Wang, S. C., \& Wang, L. L. (2021). A New Method of Measuring Human Resource Output Value: An Analysis Based on New Understanding of Value Chain. Journal of Human Resource and Sustainability Studies, 9, 541-550.

https://doi.org/10.4236/jhrss.2021.94034

Received: May 7, 2021

Accepted: November 15, 2021

Published: November 18, 2021

Copyright $\odot 2021$ by author(s) and Scientific Research Publishing Inc. This work is licensed under the Creative Commons Attribution International License (CC BY 4.0).

http://creativecommons.org/licenses/by/4.0/

\begin{abstract}
To measure enterprise's Human Resource Output Value (HROV), lots of concerned information and knowledge are needed, being faced with the conflicts derived from the mismatching of informational structures in enterprise. In enterprise's Value Chain ( $\mathrm{VC}$ ), the output value of its step-by-step production could be explicated through the pricing in internal modulated marketing transactions between Responsibility Centers (RCs), endowed with corresponding rights, responsibility, and benefits to manage their resources including Human Resource (HR). Based on the decentralized and market-oriented organizational structure along with its VC, the degree of difficulty of measuring enterprise's HROV could be reduced greatly by being decomposed at the level of RCs.
\end{abstract}

\section{Keywords}

Human Resource Output Value (HROV), Value Chain (VC), Responsibility Centers (RCs), Accounting Measurement, Human Resource Accounting (HRA)

\section{Introduction}

About enterprise's competitive power, which could be defined as the relative advantage of competitive competences comparing to its competitors, some scholars thought that it is derived from enterprise's special resources or strategic assets which are difficult to be imitated or traded (Barney, 1991), while some researchers defined its source as enterprise's core competence or dynamic competence (Prahalak \& Hamel, 1990; Klein \& Koren, 1998), and some other people regarded that it is derived from the socializational or collective knowledge exist- 
ing in the level of enterprises or other organizations (Kogut \& Zander, 1996; Spender, 1996).

Based on the analysis of the theories above, Wang (2013) put forward a model of assembly clusters composed of three clusters of enterprise's knowledge, which are that about the recognition of Customer Value (CV), about the creating and providing of the $\mathrm{CV}$, and as the base of the two knowledge clusters above existing in enterprise staff. Judged by the essential characteristics of prepay and productivity of capital, the three knowledge clusters could be defined as Customer Capital, Organizational Capital, and Human Capital, respectively. So, the structure of enterprise's Knowledge Capital could be described as Figure 1.

To facilitate the function of enterprise's competitive power system, it is necessary to measure the input value and output value of the investment for its Knowledge Capital. Human Resource Accounting (HRA) came into being for a part of the task, to measure the value variation of Human Resource, especially including Human Capital.

For the last forty years or so, the researches of HRA have appeared an up-down-up trend. After a long period of bottle-neck in 1990s, the research interests in this field have become more and more again in recent years, and the paper published in top 5 international accounting journals has increased from 5 in 2000 to 8 in 2008, and then 12 in2009 (He \& Li, 2011) $)^{1}$.

As a branch of accounting, HRA is mainly to measure and report the value of the HR in organizations (Flamholtz, 1974). The word "value" there should be identified as different meanings: the cost of HR derived from the added investment by the corresponding accounting entity such as enterprise, the output value of HR for the accounting entity, and the income value got by HR owner from the organization (Wang, 2015).

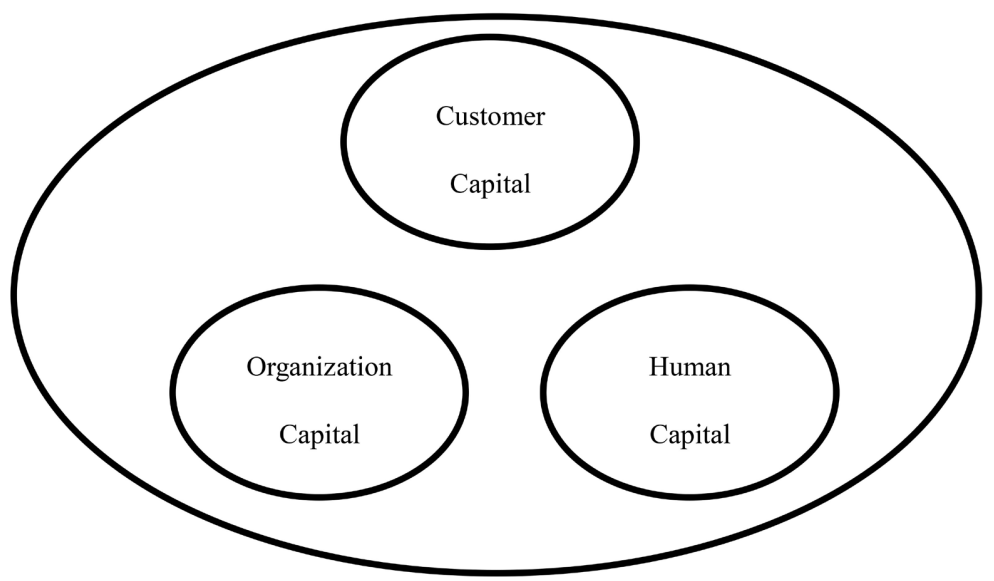

Figure 1. Structure of enterprise's knowledge capital. Source: Financial economics on competitive power by Wang, 2013.

${ }^{1}$ These top journals are Accounting Review, Journal of Accounting and Economics, Accounting, Organization and Society, Journal of Accounting Research, and Contemporary Accounting Research. 
For self-interest, lots of attention is focused on Human Resource Output Value (HROV) in sorts of organizations, especially enterprises, and its measuring is the key part of Human Resource Accounting (HRA) (Flamholtz, 1974). Only on the base of the key accounting information, is it possible to estimate whether the costing enterprise paid for the usage of Human Resource (HR) matches its outcome expected, and to assess whether the earnings its owner got from the enterprise is in conformity with the principle of fairness of incentives. In a word, measuring HROV is the core of HRA, and the key for the HR value management. However, it is almost the most difficult problem in the researches in HRA, which needs to analyze the contribution share of HR among enterprise's comprehensive income derived from its Team Production based on the union of sorts of resources, including HR (Alchian \& Demsetz, 1972).

\section{Theoretical Deduction}

\subsection{HROV}

Output Value is referred to the utility value of somewhat outcome derived from one sort of resources used in producing process, so, Human Resource Output Value (HROV) is that of human resource used in the process, which is necessary to be estimated by related parties, whose interest would be affected by the usage of the resource. The Self-motivation spurs them to collect, handle, cognize and understand relevant information and knowledge for the estimation, acting as rational persons or organizations for their own benefits.

With respect to HROV, enterprise utilizing its human resources (HR) indeed has the intent to act as a rational estimator, but it is usually confronted with the problems of Rational Shortage, for its hierarchical structure and the very complicated function of HR with lots of determinants (Wang, 2011).

The structure of information distribution about the human resources used in enterprise is usually flat, while that of information usage is usually centralized. So, the mismatching between them is the main barrier limiting the efficiency of information utilizing, with more omission, delay, distortion as the path of information transmission is prolonged (Hayek, 1945). This regularity stands especially for HROV because of its great complexity. To relieve the structural conflict, it is necessary to handle the information about HROV as soon as it is coming into being, which needs to make the structure of information usage to be flattened. In other words, the estimation of HROV should be performed by enterprise's Responsibility Centers (RCs) with direct duty, rights and benefits for HR management, which is traditionally centralized in enterprise's top management.

\subsection{Internal Transaction}

Even these reinforced RCs are authorized with rights of HR management, they still need to estimate HROV through calculating the contribution share of HR among their total output, which could be embodied mainly through the pricing 
of internal transactions between them. The prices of economic goods transferred between these RCs should be fair, with essential meanings of free negotiation and volunteer acceptance. This is to say, the internal transactions should be market-oriented, referring to the information about the operating of outside markets, especially the pricing in corresponding markets. In brief, the explicit and market-oriented internal transactions will be very useful for the assessment of HROV.

Value Chain (VC)

Based on the analysis above, we could connect our research with Value Chain shown as Figure 2 (Porter, 1985).

Some notes about the diagram of VC should be emphasized on as follows:

1) The part of arrows shows the direction of enterprise operating, the second arrow represent the direction of Enterprise Value (EV) or profit, while the first arrow means Customer Value (CV), which is added in the figure by us to emphasize the customer-oriented direction.

2) Basic Activities longitudinally reflect the course of production in an enterprise, while the auxiliary or Supportive Activities vertically reflect the course of resource allocation or management. The latter can improve enterprise's ability of creating and offering CV and realizing its EV through improving the efficiency of the former in each link and on the whole.

3) VC is not only a kind of valuable concept, but also a great analysis tool with revolutionary meanings. In the theory, enterprise could be understood as a set of activities incurring cost and creating CV. So, these activities could be finished by enterprise itself or other producers to achieve more CV or cost less.

\section{Model Constructing to Measure HROV}

\subsection{VC in Decentralized Enterprises}

As the economy based on information and knowledge is coming true, it is necessary for enterprise to allocate more resources including HR into its Basic Activities and authorize more powers to corresponding RCs to create or keep its competitive advantage on $\mathrm{CV}$.

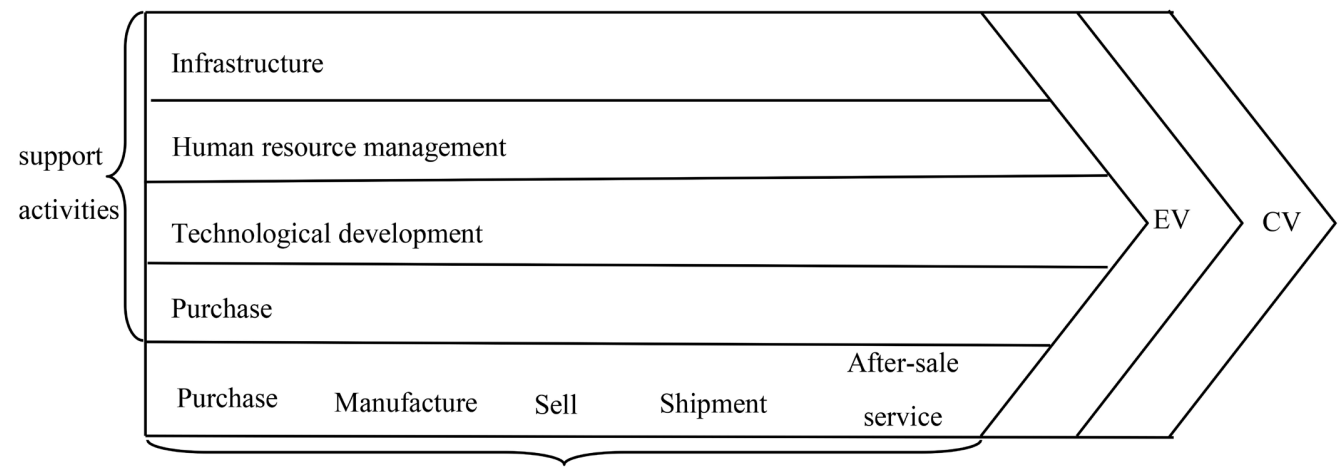

Basic activities

Figure 2. Value chain. Source: based on the model of value chain by Porter, 1985. 
In the trend of decentralization, enterprise's VC could be expressed as Figure 3.

Two key points should be given as follows:

1) Enterprise's administrative functions and powers are greatly simplified, most of them are delegated to its RCs in charge of corresponding Basic Activities.

2) Accordingly, most resources including $H R$ were managed by these grass-rooted RCs, with relatively independent property rights, which are very beneficial to make enterprise's internal transactions explicit and market-oriented, and lay the institutional base for the accounting by these RCs (Wang, 2005).

\subsubsection{Organizational Structure of Decentralized Enterprise}

In a decentralized enterprise, its organizational structure would be modified correspondingly, shown as Figure 4.

In Figure 3, a decentralized enterprise is composed of a relatively "small" administrative center and enlarged ordinary RCs, the former is in charge of enterprise's comprehensive administrative functions, though which has been simplified greatly in the structure, while the latter are responsible for specialized Basic Activities to produce targeted economic goods. These ordinary RCs act as semi-enterprises in internal market, simulating outside market mechanism to set prices for their phased and finished products.

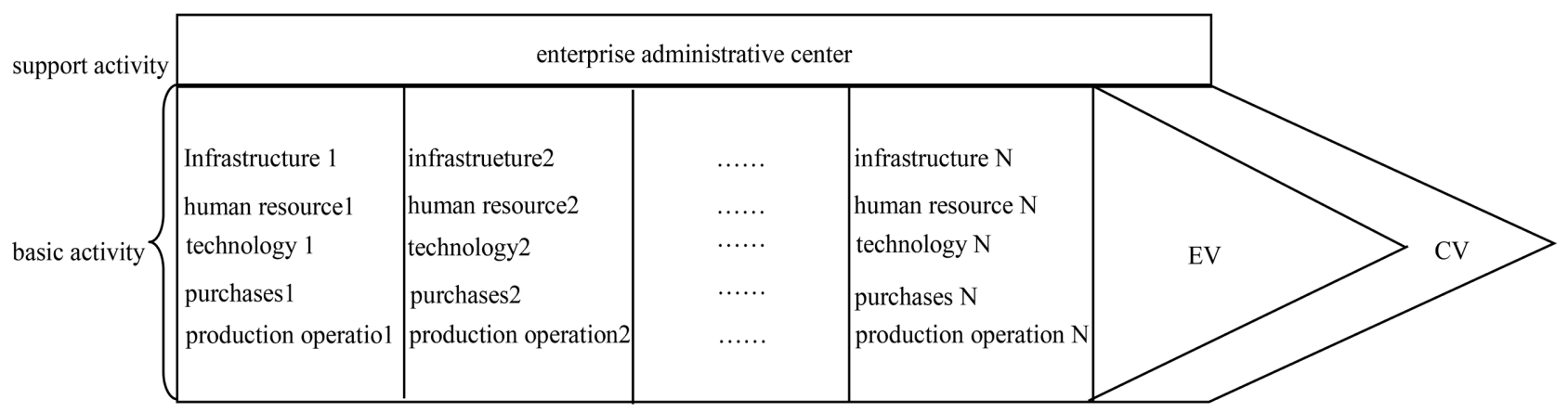

Figure 3. VC in decentralized enterprise. Source: Original work of this paper.

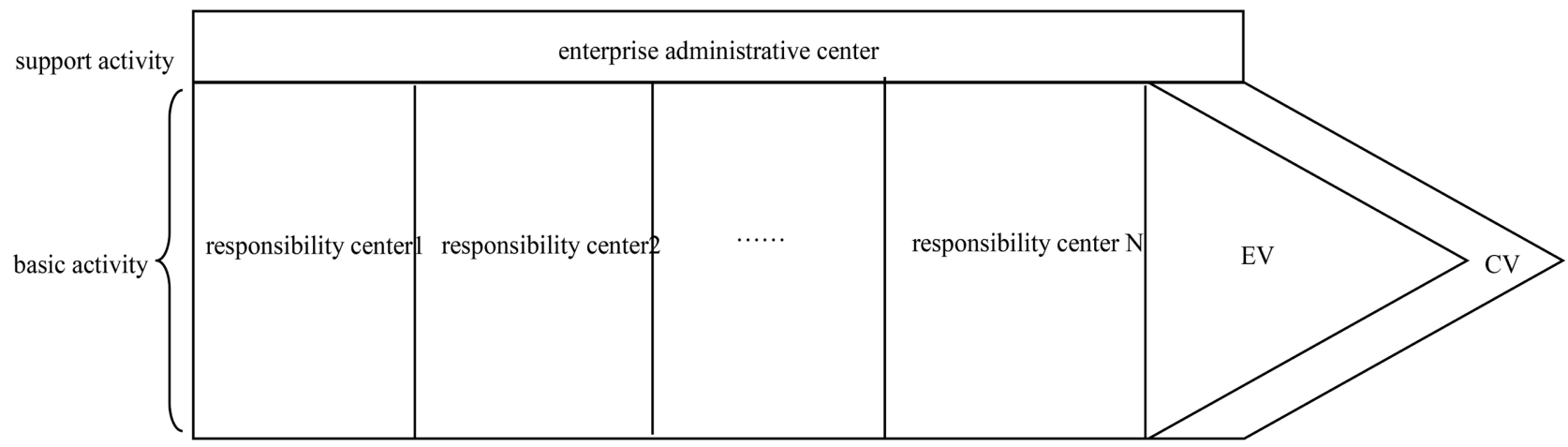

Figure 4. Organizational structure in decentralized enterprise along with its VC. Source: Original work of this paper. 


\subsubsection{Transactions between RCs}

Transactions about enterprise's phased or finished products are executived between its RCs as Figure 5.

Some instructions are necessary to be given as follows:

1) One node represents a RC in Figure 3, E represents enterprise's administrative center, which is responsible for its technological development, operating process organizing, marketing its products to external market, and other comprehensive administrative functions. While $1,2, \ldots, n$ represent enterprise's ordinary RCs in charge of sorts of resources including HR to perform some Basic Activities, whose sequence is opposite to that in Figure 3 just for usage habits, having no harm to our research results.

2) The sequence from $\mathrm{E}$ to $\mathrm{n}$ shows the notion and model of so-called "pulling model of production".

\subsubsection{Relationship between $\mathrm{E}$ and Other RCs}

E sells its holistic economic goods to outside market directly at the price labeled as $p_{E}$ forming competitive advantage relative to its competitors, with its corresponding sales volume labeled as $Q_{E}$.

The products sold by $\mathrm{E}$ were purchased from the $\mathrm{RC}_{1}$, at price of $p_{1}$ and with the volume of $Q_{1}$, which is negotiated in fair trading. In like manner, $\mathrm{RC}_{1}$ bought the "step-by-step goods" from $\mathrm{RC}_{2}$ at price of $p_{2}$ and with the volume of $Q_{2}$; these internal transactions could be prolonged to $\mathrm{RC}_{\mathrm{n}}$.

\subsubsection{HROV of Ordinary RCs}

The RCs except E could be called ordinary RCs, responsible for some specialized Basic Activities to produce theirs "step-by-step goods". Their HR could be mainly divided into three basic types: HR for producing activities (labeled as $\mathrm{hp}$ ), that for technical service such as quality controlling (labeled as ht), and that for grass-rooted management such as production planning (labeled as $\mathrm{hm}$ ).

Other resources input into Ordinary RCs' production mainly include as follows: 1) material resources, mainly including materials purchased from external markets, and fixed assets allocated by enterprise, whose value could be labeled as $C_{m} ; 2$ ) organizational capital such as technological results derived from enterprise's $\mathrm{R} \& \mathrm{D}$, corporate culture and other public resources, labeled as $K_{o}$, and customer capital such as customer relation net, labeled as $K_{\odot}$ which were both invested, managed and charged for return by $\mathrm{E}$.

Take RC1 as an example to show as following how its HROV should be measured. That of other Ordinary RCs could be measured in similar methods.

$$
V_{1}=p_{1} Q_{1}-p_{2} Q_{2}-C_{m 1}
$$

where, $V_{1}$ is the output value of RC1, $p_{1} Q_{1}$ represents its sales revenue from E; $p_{2} Q_{2}$ represents its purchase cost from RC2. $C_{m 1}$ represents the value of material resources consumed in $\mathrm{RC} 1$ itself.

In another explanation, $V_{1}$ is the complicate function of knowledge capital, which is classically divided as customer capital, structural or organizational capital, 


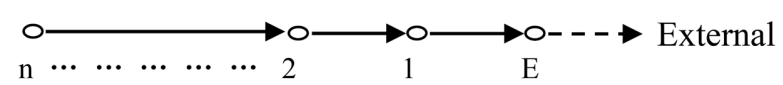

Figure 5. Transactions between enterprise's RCs. Source: Original work of this paper.

and human capital (Stewart, 1997; Wang, 2013). For an enterprise, its customer capital and organizational capital are invested and controlled by its administrative center E, who will get necessary investment return from ordinary RCs by somewhat rent embodied in the determination of $p_{1}$, and then $p_{1} Q_{1}$. So, to great degree, $V_{1}$ could be regarded as the production function of $\mathrm{HR}$ of $\mathrm{RC} 1$, expressed as follows.

$$
V_{1}=A_{1} K_{h p}^{\alpha_{1}} K_{h t}^{\alpha_{2}} K_{h m}^{\alpha_{3}}
$$

where, $K_{h p}, K_{h t}, K_{h m}$ respectively represent the number of human resource for production, technical service, and basic management. $\alpha_{1}, \alpha_{2}, \alpha_{3}$ are respectively the parameters representing the contribution share of $K_{h p}, K_{h t}, K_{h m} . A_{1}$ represents the degree of spillover or multiplier effect derived from the synergy of the types of HR.

Further, the incremental of $V_{1}$ could be formed as follows:

$$
\mathrm{d} V_{1}=\frac{\partial V_{1}}{\partial K_{h p}} \mathrm{~d} K_{h p}+\frac{\partial V_{1}}{\partial K_{h t}} \mathrm{~d} K_{h t}+\frac{\partial V_{1}}{\partial K_{h m}} \mathrm{~d} K_{h m}
$$

where,

$$
\frac{\partial V_{1}}{\partial K_{h p}}=\alpha_{1} A K_{h p}^{\alpha_{1}} K_{h t}^{\alpha_{2}} K_{h m}^{\alpha_{3}}=\frac{\alpha_{1}}{K_{h p}} V_{1}, \frac{\partial V_{1}}{\partial K_{h t}}=\frac{\alpha_{2}}{K_{h t}} V_{1}, \frac{\partial V_{1}}{\partial K_{h m}}=\frac{\alpha_{3}}{K_{h m}} V_{1}
$$

So,

$$
\mathrm{d} V_{1}=\frac{\alpha_{1} V_{1}}{K_{h p}} \mathrm{~d} K_{h p}+\frac{\alpha_{2} V_{1}}{K_{h t}} \mathrm{~d} K_{h t}+\frac{\alpha_{3} V_{1}}{K_{h m}} \mathrm{~d} K_{h m}
$$

The essential meaning of formula (4) and (5) is that, the incremental HROV of one unit added $K_{h p}, K_{h t}, K_{h m}$ is correspondingly $\frac{\alpha_{1} V_{1}}{K_{h p}}, \frac{\alpha_{2} V_{1}}{K_{h t}}, \frac{\alpha_{3} V_{1}}{K_{h m}}$, which is also approximately the average output value of one employee with special sort of HR under the existing conditions.

Of course, there exists difference between the output value of different employees even with same sort of HR. If their output value is embodied in similar or comparable economic goods, it could be measured by the quantity of qualified goods. For example, presume $n$ workers in RC1 totally finished its economic goods $Q_{1}$, so their average productivity is $Q_{1} / n$, with value measured as $\frac{\alpha_{1} V_{1}}{K_{h p}}$ above, and then the output value of an employee with production of $q$ could be measured as $\frac{\alpha_{1} V_{1}}{K_{h p}} * q /\left(Q_{1} / n\right)$.

But, if the output value of different employees, even belonging to same category of HR, is embodied in economic goods difficult to be compared with each 
other, such as quality-test service, design drawing, technical guidance at-present, and the like, how should we measure their output value? It is impossible to divide RC1 into smaller sub-RCs unlimitedly because of the cost-benefit comparability. It is relatively rational to leave the task of measuring their output value to their direct managers who are most informed about these different HR, giving a comprehensive judgment about the proportional relationship in form as a:b:c ... Though this measurement is of subjectivity in some degree, but in most practical cases, moderate accuracy is better than excessive but expensive accuracy.

\subsubsection{The HROV of $\mathrm{E}$}

The output value of enterprise's special administrative center E, labeled as $V_{e}$ could be calculated as follow:

$$
V_{e}=p_{e} Q_{e}-p_{1} Q_{1}-C_{m e}-C_{f e}
$$

In this formula, $p_{e} Q_{e}$ means its sales revenue from outside market, $p_{1} Q_{1}$ represents its procurement cost paid to $\mathrm{RC} 1, C_{m e}$ is its material costing, $C_{f e}$ is its financing cost.

From the perspective of Theory of Knowledge Capital, $V_{e}$ described above is derived from enterprise's knowledge capital, which was structured as "H-S-C" in Thomas A. Stewert's classic document. In this widely-accepted structure, $\mathrm{C}$ denotes customer capital $\left(K_{c}\right)$, which refers to enterprise's knowledge, abilities, and resources to cognize concerned Customer Value (CV), including its customer relationship network, distribution channels, customer databases, market research results, and so on. S denotes structural or organizational capital $\left(K_{o}\right)$, which refers to its knowledge, abilities, and resources to realize the CV, embodied in its strategies, plans, intellectual property rights, proprietary technologies, rules, procedures, corporate culture, and the like. $\mathrm{H}$ denotes the human capital of E, mainly including that for sale $\left(K_{h s e}\right)$, technological services $\left(K_{h t e}\right)$, and enterprise's comprehensive management $\left(K_{h m e}\right)$.

Based on the analysis above, the output value of $\mathrm{E}$ could be measured in the production function as following:

$$
V_{e}=A_{e} K c^{\beta_{1}} K_{o}^{\beta_{2}} K_{h s e}^{\beta_{3}} K_{h t e}^{\beta_{4}} K_{h m e}^{\beta_{5}}
$$

whereby, $\beta_{1}, \beta_{2}, \beta_{3}, \beta_{4}, \beta_{5}$ are respectively the parameters of $K_{c}, K_{o}, K_{h s e}, K_{h t e}$ and $K_{h m e}$ showing their contribution in the production function. $K_{c}$ and $K_{o}$ could be measured by the investment on them respectively; while $K_{h s e} K_{h t e}$ and $K_{\text {hme }}$ could be measured by the number of employees with HR for sale, technological service, and enterprise's comprehensive administrations respectively. And $A_{e}$ shows the synergy effect of all sorts of resources in E.

So,

$$
\mathrm{d} V_{e}=\frac{\beta_{1}}{K_{c}} V_{e} \mathrm{~d} K_{c}+\frac{\beta_{2}}{K_{o}} V_{e} \mathrm{~d} K_{o}+\frac{\beta_{3}}{K_{h s e}} V_{e} \mathrm{~d} K_{h s e}+\frac{\beta_{4}}{K_{h t e}} V_{e} \mathrm{~d} K_{h t e}+\frac{\beta_{5}}{K_{h m e}} V_{e} \mathrm{~d} K_{h m e}
$$

In formula (8), $\frac{\beta_{3}}{K_{h s e}} V_{e}, \frac{\beta_{4} V_{e}}{K_{h t e}}, \frac{\beta_{5} V_{e}}{K_{m e}}$ are respectively the incremental out- 
put value when $\mathrm{E}$ adds one unit of $\mathrm{HR}$ for sales, technological services or comprehensive administrations under the existing conditions.

\section{Conclusion}

To measure HROV is still an important and difficult problem in the air, preventing HRA from being widely used into practices. There exist some fatal obstacles hindering the further researches in the field, including the complicate function of lots of factors, enterprise's Team Production based on the union of sorts of resources including HR, and mismatching between the structure of information distribution and that of information usage about HR.

Our research was to measure HROV in decentralized enterprise's organizational structure along with its Value Chains, whose output value transmitted is measured through modulated internal market mechanism by RCs authorized with corresponding rights, responsibility, and benefit to realize their fair output value, and then to measure their HROV rationally. Our research has overcome in some degree the obstacles listed above, and given an effective method to measure enterprise's HROV, which is illuminating for further researches in the field, then the developing of HRA, and is valuable for the application of HRA in enterprises' management, especially their value management of $\mathrm{HR}$.

Despite these contributions in theoretical development, there exist some limitations in our study. The method of measuring HROV put forward in the paper is eager for supports of empirical evidences to be got from either case studies or statistical empirical researches. The application of the method was limited in the management of decentralized enterprises, with the conditions described above in the paper. However, these limitations will leave some clues and more space for further researches in the field.

\section{Conflicts of Interest}

The authors declare no conflicts of interest regarding the publication of this paper.

\section{References}

Alchian, A., \& Demsetz, H. (1972). Production, Information Costs, and Economic Organization. American Economic Review, 62, 1125-1148.

Barney, J. B. (1991). Firm Resources and Sustained Competitive Advantage. Journal of Management, 17, 99-120. https://doi.org/10.1177/014920639101700108

Flamholtz, E. G. (1974). Human Resource Accounting. Dickenson Publishing Company Inc.

Hayek, F. A. (1945). The Use of Knowledge in Society. American Economic Review, 4, 519-530.

He, W. T., \& Li, G. (2011). The Academic Trend of Foreign Researches on Human Resource Accounting: A Statistical Analysis Based on Top International Accounting Journals. Accounting and Finance, 5, 18-28. (In Chinese)

Klein, M., \& Koren, N. (1998). The Influence of the Thermocline on Sedimentation in the 
Deeper Part of Lake Kinneret, Israel. Limnologica 28, 293-299.

Kogut, B., \& Zander, U. (1996). What Firms Do? Coordination, Identity, and Learning. Organization Science, 7, 502-518. https://doi.org/10.1287/orsc.7.5.502

Porter, M. E. (1985). Competitive Advantage. The Free Press.

Prahalad, C. K., \& Hamel, G. (1990). The Core Competence of the Corporation. Harvard Business Review, 68, 79-91.

Spender (1996) Making Knowledge the Basis of a Dynamic Theory of the Firm. Strategic Management Journal, 17, 45-62. https://doi.org/10.1002/smj.4250171106

Stewart, T. A. (1997). Intellectual Capital: The New Wealth of Organizations. Crown Business.

Wang, Y. W. (2005). A Theory of Property Rights Relationship on the Nature of Accounting. Finance and Accounting Monthly, 1, 1-4. (In Chinese)

Wang, Y. W. (2011). Engineerization or Socialization: An Introspection on the Measuring Methods of Human Resource Accounting. Journal of Hunan Finance and Economic University, 1, 120-124. (In Chinese)

Wang, Y. W. (2013). Financial Economics on Competitive Power: An Analysis on Enterprises' Value, Capital and Competitive Power. China Renmin University Press.

Wang, Y. W. (2015). On the Theories, Methods and Usage of Human Resource Accounting. Hunan University Press. 